\title{
Food-Induced Anaphylaxis Year in Review
}

Marina Tsoumani, M.D. ${ }^{1, *}$

Vibha Sharma, M.D. ${ }^{2}$

Nikolaos G. Papadopoulos, M.D., Ph.D. ${ }^{3,4}$

\author{
Address \\ ${ }^{*}, 1$ Centre for Respiratory Medicine and Allergy, Institute of Inflammation and \\ Repair, The University of Manchester and University Hospital of South Manchester, \\ Manchester, UK \\ Email: Marina.Tsoumani@manchester.ac.uk \\ ${ }^{2}$ Department of Pediatric Allergy and Immunology, Royal Manchester Children's \\ Hospital, Manchester, UK \\ ${ }^{3}$ Centre for Paediatrics and Child Health, Institute of Human Development, The \\ University of Manchester, Manchester, UK \\ ${ }^{4}$ Allergy Departtment, 2nd Paediatric Clinic, University of Athens, Athens, Greece
}

Published online: 24 May 2015

C Springer International Publishing AG 2015

This article is part of the Topical Collection on Anaphylaxis

Keywords Food anaphylaxis · Food allergy · Anaphylaxis

\section{Opinion statement}

Food allergy is increasing; as a consequence, food-induced anaphylaxis is also becoming a growing problem. Our understanding of the mechanisms of tolerance is still basic and requires much more research before it becomes helpful in guiding our interventions. However, empirical approaches with oral immunotherapy and food introduction manipulation appear promising, although standardization is required before employing them on a large scale. Furthermore, education and public health measures can be helpful for the increasing proportion of the population at risk.

\section{Introduction}

Food-induced anaphylaxis (FIA) can be a lifethreatening emergency that requires immediate treatment and prompt actions. However, clinicians need to identify progression, as death can occur within minutes of ingestion of a reactive allergen [1] and rapid decisionmaking may alter significantly the outcome. In daily practice, diagnosis of anaphylaxis can be an arduous process $[2,3]$ especially at the first presentation, when symptoms are not typical and/or when the trigger food allergen is not obvious. Up to $20 \%$ of cases of anaphylaxis present without a rash, and in such cases, wheeze or hypotension can be confused with other acute medical conditions. This leads to inaccurate diagnosis and record of incidence, which is also represented by the difficulty in coding anaphylaxis as a diagnosis and anaphylaxis as the underlying cause of death under the International Classification of Diseases (ICD) system $[4,5]$. Where the diagnosis of an allergic reaction is established, the severity of the reaction can be underdiagnosed [6]. 
With numbers of food allergic patients increasing worldwide [7-10], it appears that the incidence of anaphylaxis is rising too, supporting the need for emphasis on the condition.

Taking the above into account, there are several unmet needs around food-induced anaphylaxis and its study is gaining momentum. A literature review and novel findings, reported in 2014, are presented in this article. Among the large volume of the literature, we aimed to identify the more novel and groundbreaking findings.
A PubMed search with the use of keywords '((food allergy AND anaphylaxis) OR (food anaphylaxis))' with a publication date within 2014 revealed 546 publications. Abstracts were screened for content, relevance and duplicates, limiting the number of studies to 119. After excluding reviews or case reports and focusing on publications with interesting and important new findings, 85 articles were retrieved in full text. Guidelines, several of which have been published in 2014, were included $[3,11 \bullet, 12-14]$; four intriguing articles published in early 2015 were added.

\section{Epidemiology of food-induced anaphylaxis}

The lifetime prevalence and incidence estimates for FIA are difficult to ascertain due to underrecognition when presenting to emergency departments [6]. Furthermore, many episodes occur in the community and are self-limiting; therefore, no medical intervention or follow-up may have been sought. In the wider context, the prevalence and real incidence of food allergy remain uncertain [8$10,15]$. Assessment of food allergy prevalence is hampered by differences in study designs, age groups, geographic regions, and dietary habits [15-18].

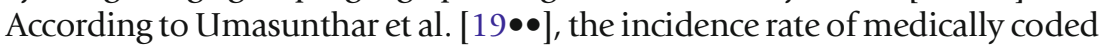
FIA in food-allergic individuals was 0.14 per 100 person years, being higher ( 0.20 per 100 person years) in the $0-19$-year age group. The highest rate (up to 7 per 100 person years) was observed in children between 0 and 4 years. Results from different studies have considerable variation; however, the general conclusion is that the rate is low.

In an attempt to record food allergy in patients with primary immunodeficiency diseases within the US Immunodeficiency Network (USIDNET), 40 of 2263 patients $(1.8 \%)$ reported food-related reactions, $20 \%$ of whom had anaphylaxis [20].

Prevalence of anaphylaxis is equally difficult to ascertain. Regional, national databases, primary care and hospital databases $[21 \bullet, 22 \bullet \bullet]$ have served as sources for extraction of anaphylaxis data. A lack of worldwide accepted clinical definition or criteria of anaphylaxis and inaccuracy in coding within the ICD coding system [23] contributes towards underdiagnosis and underreporting of FIA. The overall prevalence of anaphylaxis appears to be increasing $[21 \bullet, 22 \bullet \bullet, 24 \bullet \bullet, 25]$.

Analysis from national anaphylaxis data from the UK [22••] during the two previous decades (1992-2012) revealed that hospital admissions due to anaphylaxis have increased to seven cases per 100,000 population per annum, yet the rate of fatal cases remained unaltered $[22 \bullet \bullet, 26 \bullet]$. The cause of anaphylaxis varies among different age groups with food allergy being the main cause during the first two decades of life $[22 \bullet \bullet, 27 \bullet, 28 \bullet \bullet]$. The fatality data from

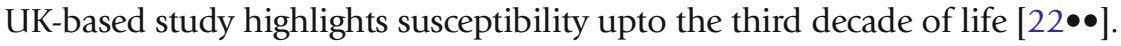

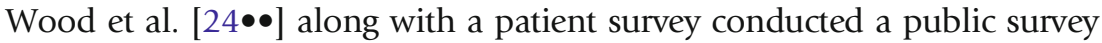
sample of 1000 adults ( $\geq 18$ years); $7.7 \%$ described a past episode of an 
anaphylactic reaction. Of these, $5.1 \%$ had a probable and $1.6 \%$ had very likely anaphylactic episodes on closer scrutiny. Food was the second commonest cause of anaphylaxis after medication.

As previously noted, medications are the commonest cause of fatal reactions in the adult population $[1,26 \bullet, 29,30]$. Food remains the most common cause of fatalities in individuals 19 years old or less [26•]. UK data showed vulnerability between 10 and 29 years of age with peanut and tree nuts causing $73 \%$ of

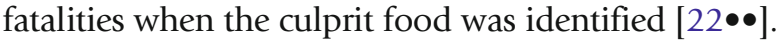

Adolescents and young adults are at greatest risk of fatality from anaphylaxis to peanuts and tree nuts [27•,31]. There is a twofold increased risk in adolescents aged 14-17 years when compared to that in children aged $0-2$ years, in a survey [32]. The cause of this higher rate in adolescents is speculated to be increased risk-taking behavior and decreased supervision by adults $[21 \bullet, 27 \bullet]$.

FIA-related hospital admissions in US children have more than doubled during the decade 2000-2010 [33]. The incidence of recurrent food reactions needing reattendance at emergency department at paediatric hospitals in Stockholm was 9 per 100 patient-years [34]. Jerschow et al. reported that $52.4 \%$ of deaths due to FIA occurred despite patients reaching emergency medical facilities [26•].

\section{Specific foods as triggers}

A large number $(>170)$ of foods have been described as potential culprits for food reactions, although the vast majority of reactions are triggered by the 'eight major food allergens' [6]. The prevalence of specific food allergies varies among different age groups and geographic regions $[6,27 \bullet, 28 \bullet \bullet, 35]$. Based on outcomes of food challenge to the eight major food allergens, the highest prevalence is of cow's milk allergy $(0.6 \%)$ with the lowest prevalence being wheat and shellfish allergy (equally $0.1 \%$ for each) [34]. In contrast, the first

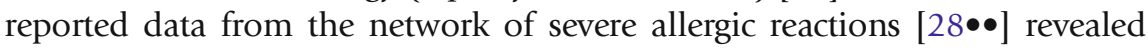
peanut (17.2\%), wheat (8.9\%), hazelnut ( $8.1 \%)$, hen's egg (6.9\%) and cow's milk $(6.5 \%)$ as the most frequent food elicitors for severe allergic reactions.

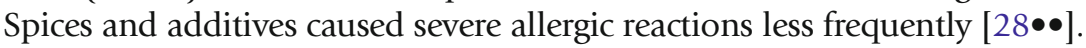

\section{Rare and unusual cases}

It is worth mentioning some reports of rare FIA cases. A case series of severe allergic reactions to lupin was published [36] suggesting that lupin is capable of causing severe reactions and that it is often omitted by food manufacturers from the ingredients list. A recent EU wide legislation enforceable by the European Food Standards Agency incorporates mandatory declaration of lupin among 14 allergens if present in the ingredients list of foods.

A case of anaphylaxis to peppermint was reported in a 69-year-old patient who was likely previously sensitized by peppermint plants he cultivated [37]. Sensitization through inhalation was also noted in a 20 -year-old woman who had an anaphylactic reaction after ingestion of rabbit meat, known to have a history of allergy on exposure to rabbit; initially she was sensitized to rabbit epithelium and urine [38]. 
A 4-month-old baby developed an anaphylactic reaction to banana, becoming the youngest case of banana anaphylaxis [39]. Hidden food ingredients are thought to be the cause in some anaphylaxis cases previously characterized as idiopathic [40]. Hamilton et al. describe anaphylaxis in a 20-year-old milk allergic female after exposure to casein found in a kickboxing glove [41].

A useful paper for allergy practitioners listed food excipients in medications [42]; nonetheless, the risk appears to be excessively low as in most cases the quantity of the food allergen in drugs and vaccines cannot elicit an allergic reaction.

By definition, FIA is an immediate illness and rarely has the form of a biphasic or protracted reaction [43]. Commins et al. found basophil activation test corresponded with a positive food challenge test in patients with anaphylaxis to oligosaccharide alpha-1,3-galactose [44•]. In addition, it appears that there is a correlation between red meat allergy and B-negative blood groups [45]. Food challenge tests with purified palm tree profilin were used to prove profilin as a cause of severe food-mediated reactions in regions with high exposure to grass [46], despite the fact that oral allergy syndrome is the most common clinical presentation.

\section{Risk factors and co-factors}

Division of risk factors for FIA into three entities: (a) augmenting factors, (b) concomitant diseases and (c) cofactors has been suggested [47].

Menstruation is considered an augmenting factor [47], and this is supported by the increased female proportion in hospital admissions for FIA in individuals more than 15 years of age; in contrast, this proportion is inverted in

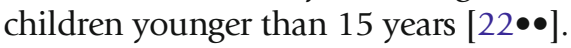

The role of female sex hormones and the mechanisms responsible are a subject under investigation [ $48 \bullet \bullet$ ]; the authors of this study raise a considerable question on whether there should be caution with sex hormonal therapy and contraceptives in patients prone to anaphylaxis.

Underlying asthma and asthma severity have been associated with foodinduced anaphylaxis $[21 \bullet, 22 \bullet \bullet, 24 \bullet \bullet]$. Turner et al. revealed that $75 \%$ of

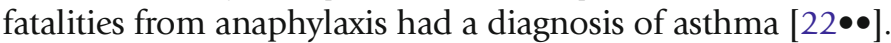

Older people are at higher risk for death by anaphylaxis; this has been attributed to cardiovascular and respiratory comorbidities [49]. Nevertheless, in FIA, the risk is highest in adolescents [21 $\bullet$.

Beta-blockers or ACE inhibitors either as monotherapy or as combined treatment are suspected cofactors, although it is debated whether underlying cardiovascular disease and age are the true causes of anaphylaxis severity in this group. With the help of a mouse model, this hypothesis was examined and there is evidence that the above medications may affect mast cell responsiveness [50].

It is thought that peanut and tree nuts $[22 \bullet \bullet, 27 \bullet, 31,51]$, especially cashew nuts, [51] are frequently related to severe reactions.

Maternal diet [52, 53] and maternal atopy [54] likely linked to epigenetic changes have been related to development of food allergy and consequently to FIA. A study by Song et al. was able to demonstrate that offspring mice from peanut allergic mothers are at increased risk of having peanut allergy through an epigenetic alteration of the IL-4 gene promoter [54]. 
Incidence rate of food anaphylaxis and its cause varies in different geographical areas dependent on food habits, disease coding, use of databases and study design $[21 \bullet, 28 \bullet \bullet$. A recent paper associated high latitude and low solar radiation with food-induced anaphylaxis in Chilean children. Vitamin D deficiency was the proposed mechanism [55].

Interaction of food allergens and lipids has been studied by different groups, and it seems that lipids alter the action of food allergens in the gastrointestinal tract in terms of access to active immune sites of the gut-associated lymphoid tissue, passage through the intestinal epithelial protein-lipid complexes, degradation process etc. Lipids can also show immunomodulation and adjuvant actions or form protein-lipid complexes [56].

The role of plasma contact system in anaphylaxis has been investigated, and Sala-Cunill et al. showed that heparin-triggered activation of the bradykinin-forming contact system is significant in anaphylaxis. Increased plasma heparin levels, bradykinin formation and the intensity of contact system activation contribute to anaphylaxis severity [57]. The latter was also shown to be augmented by estrogen through increase of tissue expression of endothelial nitric oxide synthase (eNOS) that leads to enhanced vascular permeability according to findings from an experiment with an anaphylaxis mouse model $[48 \bullet \bullet]$.

Prior to FIA, sensitization to the culprit food is required. Skin as a route of sensitization has been proposed and this is supported by several recent studies [58-60] demonstrating a correlation between fillagrin loss of function mutations, affected skin barrier and food allergy.

Impaired skin barrier leads to increased thymic stromal lymphopoietin (TSLP) expression and basophil infiltration, and it is likely that these promote intestinal allergic inflammation and risk for IgE-mediated food allergy [61].

Efforts have been made to further explore the role of FcyRIIb receptor and food-specific IgG antibodies to anaphylaxis and oral immunotherapy [62] and the contribution of eosinophils to gut immune homeostasis via activation of dendritic cells and migration to mesenteric lymph nodes [63].

Fish oil contains long-chain n-3 polyunsaturated fatty acids (n-3 LCPUFA) eicosapaentanoic acid (EPA) and docosahexaenoic acid (DHA), and it has been suggested it may prevent food allergy or atopy in children [64]. The involvement of Treg in tolerance induction by n-3 LCPUFA is under investigation, and van den Elsen et al. have shown that CD25+ Treg are crucial in preventing whey allergy in mice fed a fish oil diet [65].

Fasting can suppress immediate hypersensitivity reactions as shown in rat mast cells which had decreased degranulation activity [66].

\section{Diagnosis}

International guidelines for the diagnosis and management of anaphylaxis have been proposed $[3,11 \bullet]$. Biomarkers such as serum tryptase have not always proved helpful for the diagnosis of food-induced anaphylaxis, as the levels are not usually raised, though there have been reports suggesting the opposite [67, 
68]; nonetheless, serum tryptase results are available at a later time, hence unable to assist evaluation of the patients at their emergency department attendance and can only be used in order to confirm diagnosis.

Guidelines published in 2014 [12, 40] suggest considering use of component resolved diagnostic (CRD) tests [69] and the basophil activation test for clinical and research purposes, where personal history, skin prick tests and specific IgE tests are not conclusive. Use of the ISAC allergen array as an additional screening tool in cases of anaphylaxis of unknown cause might identify a culprit such as omega-5-gliadin or shrimp [70].

Careful interpretation of CRD results is required [68], given that clinical relevance of newly identified molecular allergens, such as the wheat component Tri a 36 [71], remains to be determined, especially for foods such as wheat where discrimination between allergy and sensitization is troublesome. Therefore, two studies from Northern Europe investigated wheat allergen components and confirmed that sensitization to gluten derived components $[72,73]$ is clinically relevant but also demonstrated the importance of dimeric alphaamylase inhibitor 0.19 [72] for wheat allergy diagnosis. Additionally, a 9-kDa wheat lipid transfer protein was described as the culprit allergen in three cases of wheat-dependent exercise-induced anaphylaxis [74].

Peanut allergen components have been thoroughly investigated, and there is a consistency in results when searching the best predictors for clinical relevance $[75,76]$. Interestingly, the use of fraction of exhaled nitric oxide ( $\mathrm{FeNO}$ ) was proposed as a safe non-invasive step of a diagnostic algorithm prior to blood collection for measuring specific IgE to Ara h 2, in order to distinguish children with peanut allergy from children tolerant to peanut all of which had a positive skin prick test to peanut with a mean wheal diameter between 3.0 and $8.9 \mathrm{~mm}$ [77].

The basophil activation test (BAT) has been added recently to the diagnostic tools for food allergy. BAT results were promising in an attempt to discriminate peanut allergic children from peanut sensitized children that tolerate peanut [78]. Basophil reactivity and sensitivity can provide additional information with regard to severity and thresholds of positive food challenges [79]. Limitations of BAT should be kept in mind, e.g., low or non-responders or its validity in allergic patients sensitized to other components [80].

Despite the progress of in vitro diagnosis, food provocation tests remain the gold standard for food allergy diagnosis. A positive result not only confirms diagnosis but more importantly can provide further clinical information and establish the threshold dose. However, even this invasive high risk and costly procedure may not be ideal: false-negative results [81], equivocal outcomes or questionable threshold levels have been reported [82•]. Food challenge symptom scoring may differ among physicians especially in the absence of objective symptoms [83]. Moreover, one could argue that challenge threshold outcomes do not represent real-life threshold levels, given that augmenting factors are lacking from a clinical setting and patients with severe or uncontrolled asthma or even patients with severe anaphylaxis are excluded from study protocols for ethical reasons. When defining the threshold dose, the time interval between increasing doses has been questioned as symptoms can manifest within $2 \mathrm{~h}$ after food ingestion, and to tackle this concern, Blumchen et al. suggested a modified prolonged food challenge protocol [82•]. Regardless, efforts have been made to determine the eliciting 
dose for common food allergens and data were pooled from clinical and research food challenge trials. This allowed estimating doses that elicit reactions in $1 \%$ of the allergic population (ED01) for peanut, cow's milk, egg

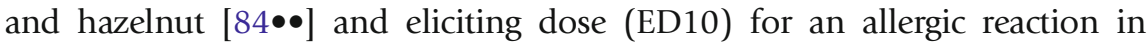

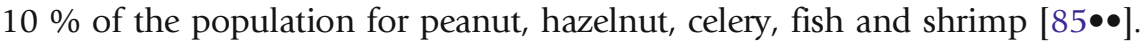
These evidence-based reference doses can support food industry in developing a more consumer-friendly precautionary labeling.

\section{Management, treatment, and prevention}

\section{Management/acute treatment}

Understanding of allergen avoidance, access to adrenaline autoinjector and management plan are essential for the clinical management of acute reactions $[3,12,40]$. Unequivocally, intramuscular administration of adrenaline is the first line treatment for anaphylaxis and under no circumstances should not be considered as such. Early administration of adrenaline may prevent a fatal outcome $[2,3,11 \bullet, 86]$. Nevertheless, anaphylaxis is undertreated even in emergency department settings, and this reflects inadequate knowledge of medical personnel on anaphylaxis [23, 87-89]. The step prior to discharge, of two adrenaline autoinjectors prescription and an allergy referral, are often omitted $[23,24 \bullet \bullet, 87,88]$. Currently, there is more than one brand of autoinjector devices available in many EU countries. A comparison study between two of these highlighted the importance of regular reinforcement of their correct technique and indications for their use [90]. There is evidence that the needle length of the adrenaline autoinjectors may be a factor of insufficient delivery of adrenaline intramuscularly in a substantial proportion of foodallergic patients, especially females, with undesirable results [91]. On the contrary, there is risk of adrenaline administration into bone with the use of an autoinjector in children weighing less than $15 \mathrm{~kg}$ [92].

With no access to second-line management, the likelihood of a recurrent episode is high, though accidental reactions can occur even in patients who have been under the care of specialists [34]. Appropriate education on food avoidance and management of future reactions are key elements of long-term management strategies [12]. Patients, parents, and care takers can benefit from well-structured education programs [93] covering first-line treatment skills, food allergy management, psychological care and social interventions. Food allergy can have a big impact on patients' quality of life. Mothers of food-allergic children are likely to suffer with anxiety and stress [94] whilst adolescents reported an unpleasant impression of social isolation induced by their food allergy [95].

Raising social awareness may also protect this vulnerable group. Better overall understanding by restaurant staff with the help of training courses might add to the effort of risk minimization of allergic reactions in the community [96]. Another step further is education of the general public especially school and camp staff.

At the public health level, precautionary allergy labeling regulation in Europe has changed since December 2014 [14, 97] where clear and detailed information on the nature of the product or the substance that can trigger reaction should be provided on the label, whereas labeling will be extended to non-prepackaged food. However, the issue of allergens present in a food due 
to cross-contamination remains unresolved and precautionary labeling statements (i.e. 'may contain' or 'trace amounts of') are confusing. Consequently, labeling issues have been linked to unexpected reactions and have led to restricted food selection for a considerable number of allergic consumers $[84 \bullet \bullet, 98 \bullet]$. More importantly, the actual risk of an allergic reaction due to allergen traces is not straightforward to calculate [98・].

Food allergy sufferers, clinicians and research groups envisage successful tolerance induction and maintenance with long-lasting effect. Effective treatments targeting immunomodulation are under development with allergen immunotherapy featuring promising results. Existing protocols are using different routes of administration, i.e. oral (OIT), sublingual (SLIT) and epicutaneous (EPIT), in addition to traditional subcutaneous immunotherapy. OIT has been used for milk, egg and peanut. Encouraging results from a randomized controlled two-phase trial that included a representative sample of UK peanut allergic children aged 7-15 years were recently published [99•]. Of the participants, 84 and $91 \%$ developed tolerance of $800 \mu \mathrm{g}$ of peanuts given daily in the first and second phase, respectively. Daily tolerance of five or even ten peanuts in some cases altered significantly patients' and their families' quality of life despite the presence of adverse reactions, mostly mild. It is not known whether discontinuation of treatment will result to loss of unresponsiveness. This was assessed by another study [100•] where children aged 1-16 years underwent a 5-year peanut OIT scheme. Treatment was discontinued, and 4 weeks later, subjects were challenged and the outcome was negative for 12 of 24 (50\%). Mechanisms of immunotherapy are still not known, and there are no predictive markers for successful treatment. However, in both OIT and SLIT reduced basophil reactivity and DC-driven $\mathrm{T}$ cell effector functions were observed [101]. Notably, immunological findings varied and even reversed throughout therapy and this might shed light to the reason behind failure of food immunotherapy to maintain unresponsiveness. For peanut allergy, OIT appears superior to SLIT at the expense of increased rate of adverse reactions [102].

Other immunomodulatory approaches are being explored such as the effectiveness of probiotic coadministration with immunotherapy [103], additional or separate treatment with antibodies $[104,105]$ and the role of distinct kinases in food allergy [104, 106]. Janus and Pim 1 kinase are part of the intracellular signaling pathway that generates cellular responses to stimuli from cytokines' and other receptors. It has been shown in mice that these kinases play a role in pathogenesis of food allergy, and their inhibition (e.g. use of ruxolitinib to inhibit Janus kinase) [104] may contribute to treatment and prevention of food allergy.

'Prevention is better than cure' and various research projects are focused on primary prevention and try to determine whether allergen avoidance or a free diet is the best strategy during pregnancy, lactation period and infancy for food allergy prevention; so far, results are controversial. European guidelines for 


\section{Research needs}

primary prevention of food allergy collected and analyzed current evidencebased recommendations in order to provide useful and simple advice to families [13] as it appears that advice given from health care professionals about introduction of other potentially allergenic foods in the diet of children with pre-existing food allergy and their siblings varies radically [107].

A prospective cohort study from the USA assessed 616 participants and found that children (mean age 7.9 years) of mothers who had higher intake of peanut, milk and wheat during early pregnancy are less likely to present with allergy and asthma $[23,52]$.

More recently, a randomized open-label controlled trial from the UK (LEAP) demonstrated that early peanut consumption on a regular basis was associated with considerably lower frequency of peanut allergy compared to the group of full avoidance of peanut products in infants at high risk of peanut allergy $[108 \bullet \bullet]$.

The role of maternal cow's milk avoidance during lactation was examined in a smaller sample (145 mother-infant pairs). The results suggested an association between cow's milk elimination from maternal diet, lower levels of mucosal specific IgA and the development of cow's milk allergy in infants [53].

Better understanding of mechanisms of tolerance is necessary for designing both preventive and therapeutic interventions. It appears that food allergy immunotherapy is feasible; however, the protocols need to be optimized. Biomarkers able to predict the risk of anaphylaxis as well as helping its diagnosis are another unmet need.

Last, but not least, educational and public health programs are required to improve the quality of life of sufferers. Recently produced guidelines need to be kept systematically up-to-date and disseminated in order to raise social awareness and improve food safety.

\section{Compliance with Ethics Guidelines}

\section{Conflict of Interest}

Marina Tsoumani received travel grant and had accommodations expenses covered or reimbursed by EAACI. Vibha Sharma received travel grants and accommodation expenses to attend conferences from MEDA, ALKabello, Stallergenes and has received grants on behalf of North West Paediatric Allergy and Network towards organising educational events from Allergy Therapeutics, Nutricia, GSK, Mead Johnson, Danone Abbott Nutrition and Nestle

Nikolaos G Papadopoulos has received funding for research from Nestle, MSD, GSK, has had consultant arrangements with AbbVie, Novartis, Menarini, MEDA, ALK-Abello, GSK, Chiesi, has received honoraria from Novartis, Uriach, GSK, Allergopharma, Stallergenes, MSD and has provided scientific advice to Abbvie, Sanofi, Menarini, MEDA

\section{Human and Animal Rights and Informed Consent}

This article does not contain any studies with human or animal subjects performed by any of the authors 


\section{References and Recommended Reading}

Papers of particular interest, published recently, have been

highlighted as:

- Of importance

• Of major importance

1. Pumphrey R. Anaphylaxis: can we tell who is at risk of a fatal reaction? Curr Opin Allergy Clin Immunol. 2004;4:285-90.

2. Simons FER, Ardusso LRF, Bilo MB, El-Gamal YM, Ledford DK, Ring J, et al. World Allergy Organization guidelines for the assessment and management of anaphylaxis. J Allergy Clin Immunol. 2011;127:587-93.

e1-e22.

3. Muraro A, Roberts G, Worm M, Bilo MB, Brockow K, Fernandez Rivas M, et al. Anaphylaxis: guidelines from the European Academy of Allergy and Clinical Immunology. Allergy. 2014;69:1026-45.

4. Tanno LK, Ganem F, Demoly P, Toscano CM, Bierrenbach AL. Undernotification of anaphylaxis deaths in Brazil due to difficult coding under the ICD10. Allergy. 2012;67:783-9.

5. Tanno L, Calderon MA, Goldberg BJ, Akdis AC, Papadopoulos NG, Demoly P. Categorization of allergic disorders in the new World Health Organization International Classification of Diseases. Clin Transl Allergy. 2014;4(1):42.

6. Huang F, Chawla K, Jarvinen KM, Nowak-Wegzyn A. Anaphylaxis in a New York City pediatric emergency department: triggers, treatments, and outcomes. J Allergy Clin Immunol. 2012;129:162-8.

7. Burks AW, Tang M, Sicherer S, Muraro A, Eigenmann PA, Ebisawa M, et al. ICON: food allergy. J Allergy Clin Immunol. 2012;129:906-20.

8. Allen JK, Koplin JJ. The epidemiology of IgE-mediated FA and anaphylaxis. Immunol Allergy Clin N Am. 2012;32:35-50.

9. Prescott S, Allen KJ. Food allergy: riding the second wave of the allergy epidemic. Pediatr Allergy Immunol. 2011;22:155-60.

10. Sicherer SH. Epidemiology of FA. J Allergy Clin Immunol. 2011;127:594-602.

11. Simons FER, Ardusso LR, Bilò MB, Cardona V, Ebisawa $\mathrm{M}$, El-Gamal YM, et al. International consensus on (ICON) anaphylaxis. World Allergy Organ J. 2014;7(1):9.

This consensus concentrated published anaphylaxis-relevant guidelines and publications by four allergy/immunology organizations and underscores the necessity of an international framework for anaphylaxis.

12. Muraro A, Werfel T, Hoffmann-Sommergruber K, Roberts G, Beyer K, Bindslev-Jensen C, et al. EAACI food allergy and anaphylaxis guidelines. Diagnosis and management of food allergy. Allergy. 2014;69:1008-25.

13. Muraro A, Halken S, Arshad SH, Beyer K, Dubois AEJ, Du Toit $\mathrm{G}$, et al. EAACI food allergy and anaphylaxis

14. Muraro A, Hoffmann-Sommergruber K, Holzhauser T, Poulsen LK, Gowland MH, Akdis CA, et al. EAACI food allergy and anaphylaxis guidelines. Protecting consumers with food allergies: understanding food consumption, meeting regulations and identifying unmet needs. Allergy. 2014;69:1464-72.

15. Nwaru BI, Hickstein L, Panesar SS, Muraro A, Werfel T, Cardona $\mathrm{V}$, et al. The epidemiology of food allergy in Europe: a systematic review and meta-analysis. Allergy. 2014;69(1):62-75.

16. McBride D, Keil T, Grabenhenrich L, Dubakiene R, Drasutiene G, Fiocchi A, et al. The EuroPrevall birth cohort study on food allergy: baseline characteristics of 12,000 newborns and their families from nine European countries. Pediatr Allergy Immunol. 2012;23(3):230-9.

17. Kim J, Chang E, Han Y, Ahn K, Lee SI. The incidence and risk factors of immediate type food allergy during the first year of life in Korean infants: a birth cohort study. Pediatr Allergy Immunol. 2011;22:715-9.

18. Park M, Kim D, Ahn K, Kim J, Han Y. Prevalence of immediate-type food allergy in early childhood in seoul. Allergy Asthma Immunol Res. 2014;6(2):131-6.

19.• Umasunthar T, Leonardi-Bee J, Turner PJ, Hodes M, Gore C, Warner JO, et al. Incidence of food anaphylaxis in people with food allergy: a systematic review and meta-analysis. Clin Exp Allergy. 2014. doi:10.1111/cea. 12477.

This thorough systematic review and meta-analysis has evaluated food-induced anaphylaxis in people with different allergies and in different age groups.

20. Tuano KS, Orange JS, Sullivan K, CunninghamRundles C, Bonilla FA, Davis CM. Food allergy in patients with primary immunodeficiency diseases: Prevalence within the US Immunodeficiency Network (USIDNET). J Allergy Clin Immunol. 2014;135(1):273-5. doi:10.1016/j.jaci.2014.09.024.

21. Tejedor Alonso MA, Moro Moro M, Múgica García MV. Epidemiology of anaphylaxis. Clin Exp Allergy. 2014. doi:10.1111/cea.12418.

This article attempts to answer questions on epidemiology of anaphylaxis based on data from various publications.

22.• Turner PJ, Gowland MH, Sharma V, Ierodiakonou D, Harper N, Garcez T, et al. Increase in anaphylaxisrelated hospitalizations but no increase in fatalities: An analysis of United Kingdom national anaphylaxis data, 1992-2012. J Allergy Clin Immunol. 2014;1-9. doi:10.1016/j.jaci.2014.10.021. Analysis of data over a 21 year period from England and Whales national and 
hospital databases were used for estimating time trend and age distribution in anaphylaxis.

23. Sclar DA, Lieberman PL. Anaphylaxis: underdiagnosed, underreported, and undertreated. Am J Med.

2014;127(1 Suppl):S1-5. doi:10.1016/j.amjmed. 2013.09.007.

24.•Wood RA, Camargo CA, Lieberman P, Sampson HA, Schwartz LB, Zitt M, et al. Anaphylaxis in America: the prevalence and characteristics of anaphylaxis in the United States. J Allergy Clin Immunol.

2014;133(2):461-7. doi:10.1016/j.jaci.2013.08.016.

This study estimated anaphylaxis prevalence in the general population based on two nationwide, cross-sectional randomdigit-dial surveys. No similar study designs for anaphylaxis prevalence and features have been previously reported.

25. Poulos LM, Waters AM, Correll PK, Loblay RH, Marks GB. Trends inhospitalizations for anaphylaxis, angioedema, and urticaria in Australia, 1993-1994 to 2004-2005. J Allergy Clin Immunol. 2007; $120: 878-84$.

26. Jerschow E, Lin RY, Scaperotti MM, McGinn AP. Fatal anaphylaxis in the United States, 1999-2010: temporal patterns and demographic associations. J Allergy Clin Immun. 2014;134(6):1318-1328.e7.

This article investigated anaphylaxis related deaths from 1999 to 2010 by extracting and analyzing data from the US National Mortality Database.

27. Gupta RS. Anaphylaxis in the young adult population. Am J Med. 2014;127(1 Suppl):S17-24. doi:10.1016/j. amjmed.2013.09.010.

A resource on epidemiology, impact, diagnosis and management of anaphylaxis in this special and high risk for anaphylaxis group.

28.•• Worm M, Moneret-Vautrin A, Scherer K, Lang R, Fernandez-Rivas M, Cardona V, et al. First European data from the network of severe allergic reactions (NORA). Allergy. 2014;69:1397-404.

First data on anaphylaxis throughout Europe collected from tertiary specialty units.

29. Liew WK, Williamson E, Tang ML. Anaphylaxis fatalities and admissions in Australia. J Allergy Clin Immunol. 2009;123(2):434-42.

30. Ma L, Danoff TM, Borish L. Case fatality and population mortality associated with anaphylaxis in the United States. J Allergy Clin Immunol. 2014;133(4):1075-83. doi:10.1016/j.jaci.2013.10.029.

31. Shah E, Pongracic J. Food-induced anaphylaxis: who, what, why, and where? Pediatr Ann. 2008;37(8):536-41.

32. Gupta RS, Springston EE, Warrier MR, Smith B, Kumar $\mathrm{R}$, Pongracic J, et al. The prevalence, severity, and distribution of childhood food allergy in the United States. Pediatrics. 2011;128:e9-17.

33. Rudders $S$, Arias S, Camargo C. Trends in hospitalizations for food-induced anaphylaxis in US children, 2000-2009. J Allergy Clin Immunol. 2014;134(4):960-2.e3.

34. Vetander M, Ly DH, Håkansson N, Lilja G, Nilsson C, Östblom E, et al. Recurrent reactions to food among children at paediatric emergency departments: epidemiology of allergic disease. Clin Exp Allergy J Br Soc Allergy Clin Immunol. 2014;44(1):113-20.

35. Nwaru BI, Hickstein L, Panesar SS, Roberts G, Muraro A, Sheikh A. Prevalence of common food allergies in Europe: a systematic review and meta-analysis. Allergy. 2014;69(8):992-1007. doi:10.1111/all.12423.

36. Bansal AS, Sanghvi MM, Bansal RA, Hayman GR. Variably severe systemic allergic reactions after consuming foods with unlabeled lupin flour: a case series. J Med Case Rep. 2014;8(1):55.

37. Bayat R, Borici-Mazi R. A case of anaphylaxis to peppermint. Allergy Asthma Clin Immunol Off J Can Soc Allergy Clin Immunol. 2014;10(1):6.

38. Martorell Calatayud C, Morales Rubio C, Bartolomé Zavala B, Ortega Sanchis S, Raducan I, Pélaez Hernández A. Allergy to rabbit meat after sensitization by inhalation. J Investig Allergol Clin Immunol. 2014;24(6):439-62.

39. O'Keefe AW, Ben-Shoshan M. A 4-month-old baby boy presenting with anaphylaxis to a banana: a case report. J Med Case Rep. 2014;8:62.

40. Sampson HA, Aceves S, Bock SA, James J, Jones S, Lang D, et al. Food allergy: a practice parameter update-2014. J Allergy Clin Immunol. 2014;134(5):1016-25.e43.

41. Hamilton RG, Scheer DI, Gruchalla R, Adkinson NF, Sampson HA. Casein-related anaphylaxis after use of an Everlast kickboxing glove. J Allergy Clin Immunol. 2015;135(1):269-71.

42. Kelso JM. Potential food allergens in medications. J Allergy Clin Immunol. 2014;133(6):1509-18. doi:10. 1016/j.jaci.2014.03.011.

quiz 1519-20.

43. Oya S, Nakamori T, Kinoshita H. Incidence and characteristics of biphasic and protracted anaphylaxis: evaluation of 114 inpatients. Acute Med Surg. 2014;1(4):228-33.

44. Commins SP, James HR, Stevens W, Pochan SL, Land $\mathrm{MH}$, King C, et al. Delayed clinical and ex vivo response to mammalian meat in patients with IgE to galactosealpha-1,3-galactose. J Allergy Clin Immunol. 2014;134(1):108-15.

This article demonstrates clear evidence of a delay in IgE-mediated food reaction with the help of provocation and ex vivo tests.

45. Sicherer SH, Leung DYM. Advances in allergic skin disease, anaphylaxis, and hypersensitivity reactions to foods, drugs, and insects in 2013. J Allergy Clin Immunol. 2014;133(2):324-34.

46. Alvarado MI, Jimeno L, De La Torre F, Boissy P, Rivas B, Lázaro MJ, et al. Profilin as a severe food allergen in allergic patients overexposed to grass pollen. Allergy. 2014;69(12):1610-6.

47. Niggemann B, Beyer K. Factors augmenting allergic reactions. Allergy. 2014;69(12):1582-7.

48.• Hox V, Desai A, Bandara G, Gilfillan AM, Metcalfe DD, Olivera A. Estrogen increases the severity of anaphylaxis in female mice through enhanced endothelial nitric oxide synthase expression and nitric oxide production. J Allergy Clin Immunol. 2015;135:729-36. 
This study investigated the effect of estradiol on anaphylaxis and proposes an explanatory underlying mechanism for increased proportion of anaphylaxis cases and severity in females.

49. Clark S, Wei W, Rudders SA, Camargo CA. Risk factors for severe anaphylaxis in patients receiving anaphylaxis treatment in US emergency departments and hospitals. J Allergy Clin Immunol. 2014;134(5):1125-30.

50. Nassiri M, Babina M, Dölle S, Edenharter G, Ruëff F, Worm M. Ramipril and metoprolol intake aggravate human and murine anaphylaxis: Evidence for direct mast cell priming. J Allergy Clin Immunol. 2014; 1-9. doi:10.1016/j.jaci.2014.09.004.

51. Johnson J, Malinovschi A, Alving K, Lidholm J, Borres MP, Nordvall L. Ten-year review reveals changing trends and severity of allergic reactions to nuts and other foods. Acta Paediatr. 2014;103(8):862-7. doi:10. 1111/apa.12687.

52. Bunyavanich S, Rifas-Shiman SL, Platts-Mills TA, Workman L, Sordillo JE, Camargo Jr CA, et al. Peanut, milk, and wheat intake during pregnancy is associated with reduced allergy and asthma in children. J Allergy Clin Immunol. 2014;133(5):1373-82.

53. Järvinen KM, Westfall JE, Seppo MS, James AK, Tsuang AJ, Feustel PJ, et al. Role of maternal elimination diets and human milk IgA in the development of cow's milk allergy in the infants. Clin Exp Allergy J Br Soc Allergy Clin Immunol. 2014;44(1):69-78. doi:10.1111/cea. 12228.

54. Song Y, Liu C, Hui Y, Srivastava K, Zhou Z, Chen J, et al. Maternal allergy increases susceptibility to offspring allergy in association with TH2-biased epigenetic alterations in a mouse model of peanut allergy. J Allergy Clin Immunol. 2014;134(6):1339-1345.e7.

55. Hoyos-Bachiloglu R, Morales PS, Cerda J, Talesnik E, González G, Camargo Jr CA, et al. Higher latitude and lower solar radiation influence on anaphylaxis in Chilean children. Pediatr Allergy Immunol. 2014;25(4):338-43.

56. Bublin M, Eiwegger T, Breiteneder H. Do lipids influence the allergic sensitization process? J Allergy Clin Immunol. 2014;134(3):521-9.

57. Sala-Cunill A, Björkqvist J, Senter R, Guilarte M, Cardona $\mathrm{V}$, Labrador $\mathrm{M}$, et al. Plasma contact system activation drives anaphylaxis in severe mast cell-mediated allergic reactions. J Allergy Clin Immunol. 2014.

58. Brough HA, Liu AH, Sicherer S, Makinson K, Douiri A, Brown SJ, et al.Atopic dermatitis increases the effect of exposure to peanut antigen in dust on peanut sensitization and likely peanut allergy. J Allergy Clin Immunol. 2014.

59. Brough HA, Simpson A, Makinson K, Hankinson J, Brown S, Douiri A, et al. Peanut allergy: effect of environmental peanut exposure in children with filaggrin loss-of-function mutations. J Allergy Clin Immunol. 2014;134(4):867-875.e1.

60. Venkataraman D, Soto-Ramírez N, Kurukulaaratchy RJ, Holloway JW, Karmaus W, Ewart SL, et al. Filaggrin loss-of-function mutations are associated with food allergy in childhood and adolescence. J Allergy Clin Immunol. 2014;134(4):876-882.e4.

61. Noti M, Kim BS, Siracusa MC, Rak GD, Kubo M, Moghaddam AE, et al. Exposure to food allergens through inflamed skin promotes intestinal food allergy through the thymic stromal lymphopoietin-basophil axis. J Allergy Clin Immunol. 2014;133(5):1390-9-1399.e1-6.

62. Burton OT, Noval Rivas M, Zhou JS, Logsdon SL, Darling AR, Koleoglou KJ, et al. Immunoglobulin E signal inhibition during allergen ingestion leads to reversal of established food allergy and induction of regulatory $\mathrm{T}$ cells. Immunity. 2014;41(1):141-51.

63. Chu DK, Jimenez-Saiz R, Verschoor CP, Walker TD, Goncharova S, Llop-Guevara A, et al. Indigenous enteric eosinophils control DCs to initiate a primary Th2 immune response in vivo. J Exp Med.

2014;211(8):1657-72.

64. Klemens CM, Berman DR, Mozurkewich EL. The effect of perinatal omega-3 fatty acid supplementation on inflammatory markers and allergic diseases: a systematic review. BJOG. 2011;118(8):916-25.

65. Van den Elsen LWJ, Meulenbroek LAPM, van Esch BCAM, Hofman GA, Boon L, Garssen J, et al. CD25+ regulatory $T$ cells transfer $n-3$ long chain polyunsaturated fatty acids-induced tolerance in mice allergic to cow's milk protein. Allergy. 2013;68(12):1562-70.

66. Nakamura S, Hisamura R, Shimoda S, Shibuya I, Tsubota K. Fasting mitigates immediate hypersensitivity: a pivotal role of endogenous D-betahydroxybutyrate. Nutr Metab. 2014;11(1):40. doi:10. 1186/1743-7075-11-40.

67. Wongkaewpothong P, Pacharn P, Sripramong C, Boonchoo S, Piboonpocanun S, Visitsunthorn N, et al. The Utility of Serum Tryptase in the Diagnosis of FoodInduced Anaphylaxis. Allergy Asthma Immunol Res. 2014;6(4):304-9.

68. Sahiner UM, Yavuz ST, Buyuktiryaki B, Cavkaytar O, Yilmaz EA, Tuncer A, et al. Serum basal tryptase may be a good marker for predicting the risk of anaphylaxis in children with food allergy. Allergy. 2014;69(2):265-8.

69. Luengo O, Cardona V. Component resolved diagnosis: when should it be used? Clin TranslAllergy. 2014;4:28. Heaps A, Carter S, Selwood C, Moody M, Unsworth J, Deacock S, et al. The utility of the ISAC allergen array in the investigation of idiopathic anaphylaxis. Clin Exp Immunol. 2014;177(2):483-90.

71. Baar A, Pahr S, Constantin C, Giavi S, Manoussaki A, Papadopoulos NG, et al. Specific IgE reactivity to Tri a 36 in children with wheat food allergy. J Allergy Clin Immunol. 2014;133(2):585-7.

72. Mäkelä MJ, Eriksson C, Kotaniemi-Syrjänen A, Palosuo $\mathrm{K}$, Marsh J, Borres M, et al. Wheat allergy in children new tools for diagnostics. Clin Exp Allergy J Br Soc Allergy Clin Immunol. 2014;44(11):1420-30.

73. Nilsson N, Sjölander S, Baar A, Berthold M, Pahr S, Vrtala $S$, et al. Wheat allergy in children evaluated with challenge and $\operatorname{IgE}$ antibodies to wheat components. Pediatr Allergy Immunol: Off Publ Eur Soc Pediatr Allergy Immunol. 2015. 
74. Pastorello EA, Farioli L, Stafylaraki C, Scibilia J, Mirone $\mathrm{C}$, Pravettoni V, et al. Wheat-dependent exercise-induced anaphylaxis caused by a lipid transfer protein and not by omega-5 gliadin. Ann Allergy Asthma Immunol. 2014;112(4):386-7.e1.

75. Nicolaou N, Poorafshar M, Murray C, Simpson A, Winell H, Kerry G, et al. Allergy or tolerance in children sensitized to peanut: prevalence and differentiation using component-resolved diagnostics. J Allergy Clin Immunol. 2010;125(1):191-7.e1-13.

76. Agabriel C, Ghazouani O, Birnbaum J, Liabeuf V, Porri F, Gouitaa M, et al. Ara h 2 and Ara h 6 sensitization predicts peanut allergy in Mediterranean pediatric patients. Pediatr Allergy Immunol. 2014;25(7):662-7.

77. Preece K, Bhatia R, Belcher J, Patchett K, McElduff P, Collison A, et al. The fraction of exhaled nitric oxide improves prediction of clinical allergic reaction to peanut challenge in children. Clin Exp Allergy J Br Soc Allergy Clin Immunol. 2014;44(3):371-80.

78. Santos AF, Douiri A, Bécares N, Wu SY, Stephens A, Radulovic $S$, et al. Basophil activation test discriminates between allergy and tolerance in peanutsensitized children. J Allergy Clin Immunol. 2014;134(3):645-52.

79. Santos AF, Du Toit G, Douiri A, Radulovic S, Stephens A, Turcanu V, et al. Distinct parameters of the basophil activation test reflect the severity and threshold of allergic reactions to peanut. J Allergy Clin Immunol. 2015;135(1):179-86.

80. Mayorga C, Gomez F, Aranda A, Koppelman SJ, DiazPerales A, Blanca-López N, et al. Basophil response to peanut allergens in Mediterranean peanut-allergic patients. Allergy. 2014;69(7):964-8.

81. Caffarelli C, Petroccione T. False-negative food challenges in children with suspected food allergy. Lancet. 2001;358(9296):1871-2.

82. Blumchen K, Beder A, Beschorner J, Ahrens F, Gruebl A, Hamelmann E, et al. Modified oral food challenge used with sensitization biomarkers provides more real-life clinical thresholds for peanut allergy. J Allergy Clin Immunol. 2014;134(2):390-398.e4.

This article suggests a modified food challenge protocol with a time interval of $2 \mathrm{~h}$ between doses when assessing threshold levels for peanut allergy as this approach is closer to real time of onset of reactions.

83. Van Erp FC, Knulst AC, Meijer Y, Gabriele C, van der Ent CK. Standardized food challenges are subject to variability in interpretation of clinical symptoms. Clin TranslAllergy. 2014;4(1):43.

84.• Allen KJ, Remington BC, Baumert JL, Crevel RW, Houben GF, Brooke-Taylor S, et al. Allergen reference doses for precautionary labeling (VITAL 2.0): clinical implications. J Allergy Clin Immunol. 2014;133(1):156-64.

This study aimed to calculate reference doses for common allergenic foods.

85.•• Ballmer-Weber BK, Fernandez-Rivas M, Beyer K, Defernez M, Sperrin M, Mackie AR, et al. How much is too much?: threshold dose distributions for 5 food allergens. J Allergy Clin Immunol. 2015; 1-8. This study estimated doses eliciting reactions in $10 \%$ of the allergic population (ED10) for 5 major common food allergens and showed a marginally different ED10 value of $2.5 \mathrm{~g}$ of protein for shrimp in comparison to hazelnut, peanut, celery and fish.

86. Dhami S, Panesar SS, Roberts G, Muraro A, Worm M, Bilò $\mathrm{MB}$, et al. Management of anaphylaxis: a systematic review. Allergy. 2014;69(2):168-75.

87. Derinoz O, Bakirtas A, Arga M, Catal F, Ergöcen S, Turktas I, et al. Pediatricians manage anaphylaxis poorly regardless of episode severity. Pediatr Int Off J Jpn Pediatr Soc. 2014;56(3):323-7.

88. Nowak RM, Macias CG. Anaphylaxis on the other front line: perspectives from the emergency department. Am J Med. 2014;127(1 Suppl):S34-44.

89. Wang J, Young MC, Nowak-Węgrzyn A. International survey of knowledge of food-induced anaphylaxis. Pediatr Allergy Immunol Off Publ Eur Soc Pediatr Allergy Immunol. 2014;25(7):644-50.

90. Robinson MN, Dharmage SC, Tang MLK. Comparison of adrenaline auto-injector devices: ease of use and ability to recall use. Pediatr Allergy Immunol Off Publ Eur Soc Pediatr Allergy Immunol. 2014;25(5):462-7.

91. Tsai G, Kim L, Nevis IF, Dominic A, Potts R, Chiu J, et al. Auto-injector needle length may be inadequate to deliver epinephrine intramuscularly in women with confirmed food allergy. Allergy Asthma Clin Immunol Off J Can Soc Allergy Clin Immunol. 2014;10(1):39.

92. Kim L, Nevis IF, Tsai G, Dominic A, Potts R, Chiu J, et al. Children under $15 \mathrm{~kg}$ with food allergy may be at risk of having epinephrine auto-injectors administered into bone. Allergy Asthma Clin Immunol Off J Can Soc Allergy Clin Immunol. 2014;10(1):40.

93. Brockow K, Schallmayer S, Beyer K, Biedermann T, Fischer J, Gebert N, et al. Effects of a structured educational intervention on knowledge and emergency management in patients at risk for anaphylaxis. Allergy. 2015;70(2):227-35.

94. Lau GY, Patel N, Umasunthar T, Gore C, Warner JO, Hanna $\mathrm{H}$, et al. Anxiety and stress in mothers of foodallergic children. Pediatr Allergy Immunol Off Publ Eur Soc Pediatr Allergy Immunol. 2014;25:236-42.

95. Sampson MA, Munoz-Furlong A, Sicherer SH. Risktaking and coping strategies of adolescents and young adults with food allergy. J Allergy Clin Immunol. 2006;117:1440-5.

96. Bailey S, Billmeier Kindratt T, Smith H, Reading D. Food allergy training event for restaurant staff; a pilot evaluation. Clin TranslAllergy. 2014;4:26.

97. Parliament E. Regulation (EU) 1169/2011 of the European Parliament and of the Council of 25 October 2011 on the provision of food information to consumers. Off J Eur Communities. 2011;L304:18.

98. Allen KJ, Turner PJ, Pawankar R, Taylor S, Sicherer S, Lack G, et al. Precautionary labelling of foods for allergen content: are we ready for a global framework? World Allergy Organ J. 2014;7(1):10. doi:10.1186/ 1939-4551-7-10. 
This article stresses the need for a global system for precautionary allergen labelling and summarizes differences of allergen labelling legislation worldwide and reviews their value for the allergic sufferers.

99.• Anagnostou K, Islam S, King Y, Foley L, Pasea L, Bond $\mathrm{S}$, et al. Assessing the efficacy of oral immunotherapy for the desensitisation of peanut allergy in children (STOP II): a phase 2 randomised controlled trial. Lancet. 2014;383(9925):1297-304.

This recent study proved efficacy of peanut oral immunotherapy and improvement of quality of life of the studied population and their families via a randomised controlled crossover trial.

100.• Vickery BP, Scurlock AM, Kulis M, Steele PH, Kamilaris J, Berglund JP, et al. Sustained unresponsiveness to peanut in subjects who have completed peanut oral immunotherapy. J Allergy Clin Immunol. 2014;133:468-75.

This study provided evidence that unresponsiveness to peanut in allergic individuals previously treated with peanut oral immunotherapy for 5 years may sustain 1 month after treatment discontinuation.

101. Gorelik M, Narisety SD, Guerrerio AL, Chichester KL, Keet CA, Bieneman AP, et al. Suppression of the immunologic response to peanut during immunotherapy is often transient. J Allergy Clin Immunol, 2014; 1-10. doi:10.1016/j.jaci.2014.11.010.

102. Narisety SD, Frischmeyer-Guerrerio PA, Keet CA, Gorelik M, Schroeder J, Hamilton RG, et al. A randomized, double-blind, placebo-controlled pilot study of sublingual versus oral immunotherapy for the treatment of peanut allergy. J Allergy Clin Immunol. 2014. doi:10.1016/j.jaci. 2014.11.005.

103. Tang ML, Ponsonby AL, Orsini F, Tey D, Robinson M, $\mathrm{Su}$ EL, et al. Administration of a probiotic with peanut oral immunotherapy: a randomized trial. J Allergy Clin Immunol. 2015;135:737-44.

104. Yamaki K, Yoshino S. Remission of food allergy by the Janus kinase inhibitor ruxolitinib in mice. Int Immunopharmacol. 2014;18(2):217-24.

105. Manohar M, Nadeau KC. The potential of anti-IgE in food allergy therapy. Curr Treat Opt Allergy. 2014;1(2):145-56.

106. Wang M, Gelfand EW. Targeting Pim1 kinase in the treatment of peanut allergy. Expert Opin Ther Targets. 2014;18(2):177-83.

107. McHenry M, Watson W. Impact of primary food allergies on the introduction of other foods amongst Canadian children and their siblings. Allergy Asthma Clin Immunol. 2014;10:26.

108.• Du Toit G, Roberts G, Sayre PH, Bahnson HT, Radulovic S, Santos AF, et al. Randomized trial of peanut consumption in infants at risk for peanut allergy. N Engl J Med. 2015;372:803-1.

This study demonstrated that early peanut consumption could prevent high-risk sensitized and non-sensitized infants from developing peanut allergy. 